\title{
PRODUÇÃO DE ADUBO ORGÂNICO PARA A IMPLEMENTAÇÃO E COOPERAÇÃO A PRODUÇÃO DOS AGRICULTORES FAMILIARES DO MUNICIPIO DE CODÓ-MA
}

\section{ORGANIC FERTILIZER PRODUCTION FOR IMPLEMENTATION AND COOPERATION THE PRODUCTION OF FAMILY FARMERS OF THE MUNICIPALITY OF CODÓ-MA}

Yago de Medeiro Silva ${ }^{1}$; Antonio Afonso Leite Monteiro $^{2}$; Lucas Eduardo Rocha de Sousa ${ }^{3}$; Dayvid Rafael Araújo Mendes ${ }^{4}$; Carmém Valdenia da Silva Santana ${ }^{5}$

DOI: https://doi.org/10.31692/978-65-991061-7-0.457-460

\section{INTRODUÇÃO}

A agricultura orgânica abrange todos os sistemas agrícolas que promovem a produção sustentável de modo ambiental, social e economicamente responsável (Lei 10.831/2003 e o Decreto 6.323/2007). Com isso, segundo Busato (2008), o princípio da adubação orgânica é ativar e manter a vida do solo. O seu uso procura imitar os processos naturais de ciclagem dos nutrientes, com a incorporação de resíduos animais e vegetais com a função de oferecer nutrientes as culturas e melhorar as características do solo. Os restos culturais, a queda de folhas, a morte de animais e microrganismos devolvem para o solo a matéria orgânica da qual eles são formados (BUSATO, 2008).

A compostagem é uma técnica idealizada para obter, no mais curto espaço de tempo, a estabilização ou humificação da matéria orgânica que na natureza se dá em tempo indeterminado. É um processo controlado de decomposição microbiana de uma massa heterogênea de resíduos no estado sólido e úmido (NUNES, 2009).

O uso da matéria orgânica na adubação de culturas é essencial para a melhoria da qualidade do solo e manutenção da fertilidade, contribuindo significativamente para a manutenção da umidade e da temperatura do solo a níveis adequados para o desenvolvimento do sistema radicular e da parte aérea das plantas, contribuindo para a melhoria da produtividade e para a sustentabilidade do sistema de produção (NUNES, 2009). Destaca-se então a importância da produção de adubos orgânicos pela compotagem para os agricultores familiares para complementação na sua produção.

A referida atividade buscou determinar o aprendizado prático em produção de

\footnotetext{
${ }^{1}$ Bacharelado em Agronomia, Instituto federal de Educação Campus Codó, yahgo.medeiros.silva@ hotmail.com

${ }^{2}$ Bacharelado em Agronomia, Instituto federal de Educação Campus Codó, afonso.lemon99@gmail.com

${ }^{3}$ Bacharelado em Agronomia, Instituto federal de Educação Campus Codó, dayvidraf92@ gmail.com

${ }^{4}$ Bacharelado em Agronomia, Instituto federal de Educação Campus Codó, sousa.eduardo@acad.ifma.edu.br

${ }^{5}$ Doutora, Instituto federal de Educação Campus Codó, carmem.santana@ifma.edu.br
} 
compostagem com restos orgânicos a implementação de uma agricultura orgânica e produção agrícola ecologicamente equilibrada com finalidade de minimizar os custos e visar ampliação da produção dos agricultores familiares do município de Codó.

\section{RELATO DE EXPERIÊNCIA}

Atualmente têm-se utilizado muito a adubação química na produção de substratos para a produção de alimentos, nisso diversos problemas são acarretados por esse tipo de produção. Problemas como a lixiviação desses materiais químicos tem alterado o equilíbrio no meio ambiente, sendo a fauna e a flora prejudicada. Além de ser origem de diversos problemas é um recurso caro e muitas vezes inacessível aos agricultores familiares.

No entanto, existem alternativas para a substituição do uso de adubos químicos, sendo um destes a compostagem que implementa e também é uma forma produção sustentável e simples de produzir.

Na produção da leira de compostagem foram utilizados esterco de bovino, restos de jardim, restos vegetais, cascas de ovos, borra de café e cinza, sendo que estes materiais foram colocados em camadas, um sobre o outro, a fim de se obter um bom resultado em absorção de nutrientes presentes em cada material, para que haja boa decomposição dos compostos e consequentemente, formação de biomassa, sem produzir compostos nocivos ao meio ambiente.

A leira foi montada em camadas, cada camada foi composta por um tipo de material orgânico já citado. Ao final do processo de produção e, conforme o passar dos dias, a leira era irrigada constantemente e revolvida, quando necessário, devido às chuvas constantes que afetava a temperatura, tornando a leira fria e úmida. As equipes faziam o revolvimento quando se notava uma temperatura baixa, atingindo às vezes $35^{\circ} \mathrm{C}$.

Com os procedimentos práticos utilizados, a leira de compostagem obteve $1,20 \mathrm{~m}$ de comprimento e $95 \mathrm{~cm}$ de largura, obtendo ao final do processo uma forma triangular. Após 20 dias, a temperatura já havia aumentado bastante, chegando a atingir 47 graus Celsius, entretanto, em decorrência de intensas chuvas posteriores e encharque da leira, a temperatura baixou consideravelmente, atingindo 35 graus Celsius. Foi necessário fazer o revolvimento da leira, a fim de estabilizar a temperatura para que o composto pudesse ficar em condições necessárias para devidas utilizações.

Após um mês, a leira de compostagem já havia diminuído de tamanha quase pela metade, ficando com $60 \mathrm{~cm}$ de altura, devido a ação da microbiota; também a sua temperatura 
já havia diminuído consideravelmente, conforme as ações de reviragens feitas pelas equipes, a fim de umedecer e estabilizar o material.

Logo, indica-se que o processo de revolvimento da leira de compostagem serve para entrada de oxigênio $\left(\mathrm{O}_{2}\right)$ e controle da temperatura, junto com o umedecimento diário da mesma, assim ocasionando a permanência e melhora da microbiota que fazem a decomposição do material orgânico. Observou-se também que a técnica de reviragens e irrigação das camadas serviram para agregar o material posto e melhorar a umidade do mesmo.

Imagem 1: Leira finalizada, após todas as camadas serem postas.. Fonte: Própria

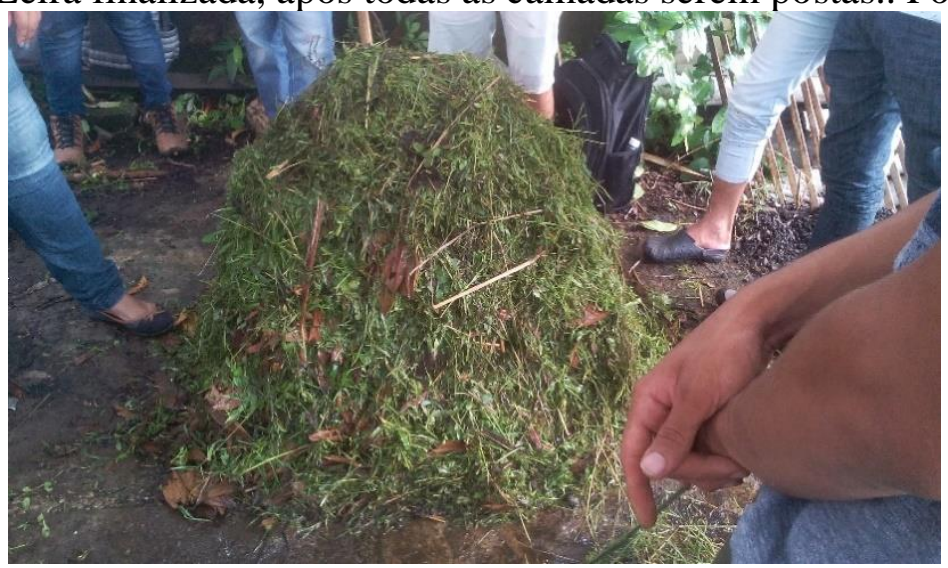

\section{CONSIDERAÇÕES}

Deste modo, todo o processo prático realizado na atividade obteve resultados significativos, tanto como para o aprendizado de forma geral das atividades executadas, como no retorno dos materiais produzidos e também nos procedimentos enfatizados na disciplina de Ecologia Agrícola, realizados com êxito, havendo acréscimo aos conhecimentos dos agricultores presentes. Ao decorrer da atividade os agricultores se mantiveram sempre curiosos sobre a transformação dos materiais orgânicos, e os nutrientes presentes no final do processo. Foi muito debatido ao final da atividade as vantagens que esse material traria em relação a produção de mudas e os seus outros diversos usos na agricultura.

A realização da atividade foi especialmente contribuinte ao aprendizado das etapas no processo de produção da leira da compostagem. A prática ajudou a conscientizar e sensibilizar os agricultores no uso de adubos orgânicos em substituição dos adubos químicos, trazendo-o a prática sustentável da produção do composto orgânico.

\section{REFERÊNCIAS}

BUSATO, J. G. Química do húmus e fertilidade do solo após adição de adubos orgânicos. Tese (Doutorado em Produção Vegetal) - Universidade Estadual do Norte Fluminense Darcy Ribeiro, Campos dos Goytacazes, 135 fls. 2008. 
NUNES, M.U.C. Compostagem de resíduos para produção de adubo orgânico na pequena propriedade. Circular Técnica, 59. Ministério da Agricultura, Pecuária e Abastecimento. Aracaju, Dezembro, 2009.

SARTORI, V. C.; SILVA-RIBEIRO, R. T.; SCUR, L.; PANSERA, M. R.; RUPP, L. C. D.; VENTURIN, L. Adubação verde e compostagem: estratégias de manejo do solo para conservação das águas. Caxias do Sul, RS: Educs, 2011. 